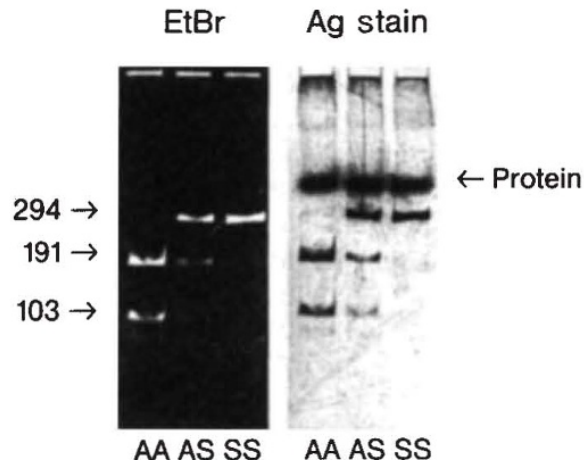

Fig. 2 Polyacrylamide gel electrophoresis of the $O x a$ NI-digested amplified DNA from normal control (AA), sickle cell trait (AS) and sickle cell anaemia (SS). The two primers used were 5'-GGGCTGGGCATAAAAGTCA -3' and 5'-AATAGACCAATAGGCAGAG-3'. DNA amplification as in Fig. 1, followed by digestion of a $10-\mu \mid$ aliquot of the reaction mixture with 10 units of $O x a \mathrm{NI}$ in a $20-\mu \mathrm{l}$ mixture for $1 \mathrm{~h}$ at $37^{\circ} \mathrm{C}$ according to the manufacturer's conditions. Two $\mu \mathrm{l}$ of $0.25 \%$ bromophenol blue was then added to the digestion mixture and electrophoresis was performed as in Fig. 1, after which the same gel was stained with ethidium bromide $(\mathrm{EtBr})$ or silver $(\mathrm{Ag})$ stain. The latter also stains a protein band.

with ultraviolet light in a darkroom, or by silver staining ${ }^{14}$, which enables the DNA bands to be seen directly and with the same degree of sensitivity as the ethidium bromide stain (Fig. 2, right).

A major advantage of this method is its simplicity. We have performed the polymerase chain reaction on lysed chorionic villus samples without prior DNA extraction", and by initiating amplification on lysed cells according to Saiki et al. . Thus, the prenatal diagnosis procedure is reduced to the following steps. Fetal cells are lysed and the appropriate polymerase chain reaction performed for 30 cycles, which can be easily accomplished by incubating the tubes sequentially in three water baths at the desired temperatures. For $\alpha$-thalassaemia, an aliquot of the reaction is immediately fractionated by gel electrophoresis, while for sickle cell anaemia an aliquot is first digested for one hour with $O x a$ NI. This part of the test is no more difficult than routine haemoglobin electrophoresis. After staining the gels, the mutations can be directly detected. Diagnosis can be completed in 3 to 4 hours.

Both specific amplification and direct visualization of polymorphic DNA sequences have been used for linkage analysis and for carrier detection and prenatal diagnosis of haemophilia $A^{8}$. Our data show that this simple non-radioactive method can readily and directly diagnose genetic disorders that are due to gene deletions or to mutations which alter restriction endonuclease cleavage sites.

We thank Henry Erlich for helpful discussions, and Scott Kogan and Jane Gitschier for communicating to us their work on haemophilia A. This work was suppor- tides encoding GKIPW of visna pol and GKVPW of MPB are identical. Considering that the probability of this alignment occurring at random is $4.3 \times 10^{-8}$, visna may have evolved this sequence to mimic the MBP mRNA sequence as a way of disrupting MBP metabolism in sheep oligodendrocytes. This might represent a type of intracellular molecular mimicry that could be a contributing cause of certain characteristics of visna infections, such as persistance and demyelination.

As retroviruses are already being investigated for involvement in multiple sclerosis ${ }^{7}$, our observations might inspire a more specific search for a lentivirus with an ability to mimic MBP sequences in human oligodendrocytes.

Patrick R. Carnegie Michael J. Weise

Department of Neurology,

Alter, B.P. Blood 64, 329-340 (1984)

Cao, A., Pirastu, M \& Rosatelli, C. Br. J. Haemai. 63. $215-220(1986)$

Withamson, R. et al. Lancet ii. 1125-1127 (1981)

Old, J.M. et al. Lancet ii, $763-767$ (1986)

Saiki. R.K. et al. Science 230, 1350-1354 (1985).

Saiki, R.K. Bugawan, T.C., Horn, G.T., Mullis, K.B. \& Erlich, H.A. Nature 324, 163-166(1986).

Chien, A., Edgar, D.B. \& Trela, J.M. J. Bact. 127 $1550)-1557$ (1976)

8. Kogan, S., Doherty, M. \& Gitschier, J. N. Engl. J. Med. (in the press).

Weatherall, D.J. \& Clegg. J.B. The Thalassuemia Syndromes 3rd edn (Blackwell, Oxford, 1981).

10. Winchagoon, P elal EMBOJ 3, 1813-1818(1984).

11. Lauer, J., Shen, C.K.J. \& Maniatis, T.J. Cell 20, $119-130$ (1980)

12. Chang, J. \& Kan, Y.W. New Engl. J. Med. 307. 30-32 (1982).

13. Orkin, S.H., Little, P.F.R., Kazazian, H.H. Jr \& Boehm, C.D. New Engl. J. Med. 307, 32-36 (1982).

14. Merril, C.R., Goldman, D.. Sedman, A. \& Ebert, M.H. Science 211, 1437-1438 (1981).

15. Goossens, M. \& Kan, Y.W. Meth. Enzym. 76, 805-817 (198i)

\section{Visna and myelin basic protein}

SIR-The demyelination caused by visna virus in sheep has long been considered to be one of the best animal models for multiple sclerosis, but the mechanism for the persistence and slow rate of tissue damage remains obscure

While we were searching known protein sequences in the Protein Identification Resource (National Biomedical Research Foundation) for homologies between an unusually hydrophobic peptide present in sheep ${ }^{2}$ and the human $21.5 \mathrm{~K}$ myelin basic protein $^{3}$ (MBP), we found the following homology between visna pol and MBP (single-letter code):

MBP SGK V P W-L K P GR

Visna pol T G K I P W I L L P G R

This region is at the junction of sequences coded by exons 1 and 2 in the MBP gene. As threonine and isoleucine should be functionally similar to serine and valine, the observed homology appears as striking as any reported to support 'molecular mimicry ${ }^{5.6}$ as a basis for demyelinating diseases. Only about six amino acids are required for an antigenic determinant, so it is likely that an immune response to this region of the visna protein could cross react with MBP. Thus, there is potential for an immunological molecular mimicry.

The homology is even more striking when the messenger RNA sequences are considered. All but one of the 15 nucleo-
Medical University of South Carolina, Charleston, South Carolina 29425, USA

1. Haase, A.T. J. infect. Dis. 153, 441-447 (1986).

2. Carnegie, P. R. \& Dowse. C. A. Science 223, 936-938 (1984) Kamholz, J. et al. Proc. natn. Acad. Sci. U.S.A. 83, 49624966 (1986).

Sonigo, P. et al. Cell 42, 369-382 (1985)

5. Jahnke, U. Fischer, E.H. \& Alvord, E.C. Science 229, 282 284 (1985).

6ujinami. R.S. \& Oldstone, M.B.A. Science 230, 1043-1045 (1985)

Koprowski, H. et al. Nature 322. 178 (1986).

\section{Enzyme identity maintained}

SIR-In his recent News and Views' article, Roger Pain rightly draws attention to the remarkable discovery ${ }^{2}$ (see also ref. $3)$ that the $\beta$-subunits of the tetrameric $\left(\alpha_{2} \beta_{2}\right)$ enzyme prolyl-4-hydroxylase are identical to the polypeptides comprising the dimeric enzyme protein disulphideisomerase (PDI). In his analysis of this unexpected example of cellular parsimony, however, Pain's emphasis is misplaced. In suggesting that PDI "has been viewed in the wrong light all along" and that its mechanism of action involves a notional affinity for prolyl residues, he ignores extensive evidence on the distribution, properties and active site of PDI.

It has long been known that in most tissues 'inactive' $\beta$-subunits of prolyl hydroxylase are in great excess (50-fold in adult mammalian liver) of those found associated with the holoenzyme ${ }^{4}$. Indeed, the question had been raised whether its involvement in the hydroxylase was this polypeptide's primary function ${ }^{4}$.

The recent papers from Kivirikko and colleagues $^{2.3}$ resolve this question; the primary function of these subunits is as PDI. Only in tissues actively synthesizing collagen is a significant proportion recruited by $\alpha$-subunits to form prolyl-4hydroxylase tetramers. The accompanying table shows the proportion of cell protein found as PDI dimers and as $\beta$ subunits of prolyl-4-hydroxylase tetramers in some secretory tissues. Note that even 